\title{
Energy expenditure in early infancy
}

\author{
By PETER. S. W. DAVIES, G. EWING AND A. LUCAS \\ MRC Dunn Nutrition Unit, Downhams Lane, Milton Road, Cambridge CB4 1 XJ
}

(Received 30 November 1988 - Accepted 2 June 1989)

\begin{abstract}
The measurement of energy expenditure has wide applications in clinical and scientific studies. Ethical and practical problems, however, have limited the acquisition of information on total energy expenditure in infancy. The doubly-labelled-water technique, recently validated for use in infants, has now been used to measure, non-invasively, total energy expenditure in a cohort of forty-one normal, full-term infants at or close to $1 \cdot 5,3$ and 6 months of age. Mean total energy expenditure was 270,280 and $330 \mathrm{~kJ} / \mathrm{kg}$ per $d$ at these ages. Centiles for total energy expenditure in early infancy are presented; it is suggested such data are most appropriately expressed as $\mathrm{kJ} / \sqrt{ }(\mathrm{kg}$ body-weight per d). These findings will be of importance in the re-evaluation of energy requirements in infancy and in the study of lesions in energy metabolism in disease states at this age.
\end{abstract}

Energy expenditure: Infancy

Knowledge of total energy expenditure is of major biological and clinical importance, particularly during infancy. This information is required for the estimation of recommended daily amounts of food energy (Department of Health and Social Security, 1979), and is essential for designing artificial infant feeds. Moreover, normal values for total energy expenditure are required as reference standards for studies on lesions in energy metabolism in disease states such as cystic fibrosis (Shepherd et al. 1988), congenital heart disease, and obesity (Roberts et al. 1988 b).

Such information is lacking due to the practical and ethical problems of measuring total energy expenditure in infants. Long-established techniques for measuring total energy expenditure using direct or indirect calorimetry are unacceptable in childhood since they require that the subject is isolated for long periods. Recently, the doubly-labelled-water technique for measuring total energy expenditure non-invasively in free-living subjects has been validated in infants (Roberts et al. 1986; Jones et al. 1987). We have used this technique to derive values for total energy expenditure in a cohort of healthy British children; in the present study we present values for infants up to 6 months of age.

\section{METHODS}

Forty-one full-term healthy infants were recruited for the study within $5 \mathrm{~d}$ of birth. In the first 3 months approximately half the cohort (twenty-one subjects) were exclusively breastfed and the remaining infants were fed on a cow's milk formula. By 6 months of age all infants had been introduced to weaning foods. Measurements of total energy expenditure were made over a period of $7 \mathrm{~d}$ on three occasions, the study period ending at or close to 6 weeks, 3 months and 6 months of age; periods A, B and C respectively.

Total energy expenditure was measured using the doubly-labelled-water technique. Two stable, non-toxic isotopes of water $\left(\mathrm{H}_{2}{ }^{18} \mathrm{O}\right.$ and $\left.{ }^{2} \mathrm{H}_{2} \mathrm{O}\right)$ were administered orally. In breastfed infants the dose was most easily administered by allowing the infant to suck on a nasogastric tube attached to a syringe containing the dose. Usually no pressure was required on the plunger of the syringe, the infant's sucking being sufficient to draw the dose 
from the syringe. In formula-fed infants the dose was added to approximately $10 \mathrm{ml}$ 'readyto-feed' formula in a standard feeding bottle. In each case the weight of dose given was determined to five decimal places. A dose consisting of $0.28 \mathrm{~g} / \mathrm{kg}$ body-weight of $14.6 \%$ $\mathrm{H}_{2}{ }^{18} \mathrm{O}$ and $0 \cdot 1 \mathrm{~g} / \mathrm{kg}$ body-weight $99 \%{ }^{2} \mathrm{H}_{2} \mathrm{O}$ was used. A single urine sample was collected immediately before administration of the dose to determine natural concentrations of ${ }^{2} \mathrm{H}_{2} \mathrm{O}$ and $\mathrm{H}_{2}{ }^{18} \mathrm{O}$ in body fluids. Urine samples were then collected $5 \mathrm{~h}$ post-dose and thereafter a timed sample was collected every $24 \mathrm{~h}$ for $7 \mathrm{~d}$. Isotopic enrichment of the urine samples was measured relative to a local standard by isotope-ratio mass spectrometry (Aqua-Sira model; VG Isogas, Cheshire). Results were expressed as \%o (per ml) enrichment relative to a local standard,

$$
\% \text { enrichment }=\frac{R_{\mathrm{S}}-R_{\mathrm{R}}}{R_{\mathrm{R}}} \times 10^{3},
$$

where $R_{\mathrm{S}}$ and $R_{\mathrm{R}}$ are the isotope ratios of the sample and reference water respectively.

In this laboratory linear regression equations are obtained from the log transformed enrichments of ${ }^{2} \mathrm{H}$ and ${ }^{18} \mathrm{O} v$. time. The regression coefficients are therefore the disappearance rates, $k_{\mathrm{t}}$ and $k_{\mathrm{o}}$ of ${ }^{2} \mathrm{H}$ and ${ }^{18} \mathrm{O}$ respectively.

The dilution space of each isotope at the beginning of the study period is calculated as

$$
N=\frac{T A}{a} \times \frac{E_{\mathrm{a}}-E_{\mathrm{t}}}{E_{\mathrm{s}}-E_{\mathrm{p}}}
$$

where $N$ is dilution space ( $\mathrm{g}$ ), $A$ is dose of isotope given $(\mathrm{g}), a$ is the portion of the dose retained for mass spectrometer analysis $(\mathrm{g}), T$ is tap water in which the portion $(a)$ is diluted (g), $E_{\mathrm{a}}$ is enrichment of the portion, $E_{\mathrm{t}}$ is enrichment of tap water, $E_{\mathrm{s}}$ is the antilog of the intercept of the regression line, $E_{\mathrm{p}}$ is enrichment of pre-dose urine sample.

In fast-growing infants it is also necessary to account for the changing size of the isotopedilution spaces during the study period. Dilution space at the end of the study period was estimated by assuming proportional increases in dilution spaces and weight gain over the study period. An 'average' dilution space was calculated as

$$
N=\frac{N_{1}-N_{2}}{\ln \left(N_{1} / N_{2}\right)},
$$

where $N_{1}$ and $N_{2}$ are the dilution spaces at the beginning and end of the study period respectively. This allows for an exponential change in $N$ between times 1 and 2.

Crude output rates of water and carbon dioxide $\left(r^{\prime} \mathrm{H}_{2} \mathrm{O}, r^{\prime} \mathrm{CO}_{2}\right.$, expressed as g equivalent $\mathrm{H}_{2} \mathrm{O} / \mathrm{d}$ ) were calculated as

$$
\begin{aligned}
r^{\prime} \mathrm{H}_{2} \mathrm{O} & =N_{\mathrm{d}} \times k_{\mathrm{d}}-Q_{\mathrm{d}}, \\
r^{\prime} \mathrm{H}_{2} \mathrm{O}+r^{\prime} \mathrm{CO}_{2} & =N_{\mathrm{o}} \times k_{\mathrm{o}}-Q_{0} .
\end{aligned}
$$

Therefore,

$$
r^{\prime} \mathrm{CO}_{2}=\left(N_{0} \times k_{0}-Q_{0}\right)-\left(N_{\mathrm{d}} \times k_{\mathrm{d}}-Q_{\mathrm{d}}\right) \text {, }
$$

where $Q_{\mathrm{d}}$ and $Q_{\mathrm{o}}$ are the changes in isotope-dilution space $(\mathrm{g} / \mathrm{d})$ over the study period.

True output rates of water and carbon dioxide were calculated taking into account the proportion of water fractionated $(x)$ in infancy, and values for fractionation of ${ }^{2} \mathrm{H}$ and ${ }^{18} \mathrm{O}$ in water vapour and ${ }^{18} \mathrm{O}$ in $\mathrm{CO}_{2}$. The value of $x$ used in the present study was $0 \cdot 13$. True output rates were calculated thus:

$$
\begin{aligned}
& r \mathrm{H}_{2} \mathrm{O}=0.93 \times x \times r^{\prime} \mathrm{H}_{2} \mathrm{O}+(1-x) r^{\prime} \mathrm{H}_{2} \mathrm{O}, \\
& r \mathrm{H}_{2} \mathrm{O}+r \mathrm{CO}_{2}=0.99 x \times r^{\prime} \mathrm{H}_{2} \mathrm{O}+(1-x) \times r^{\prime} \mathrm{H}_{2} \mathrm{O}+1 \cdot 04\left(r^{\prime} \mathrm{CO}_{2}\right)
\end{aligned}
$$

these equations rearrange to

$$
\begin{aligned}
& r \mathrm{H}_{2} \mathrm{O}=r^{\prime} \mathrm{H}_{2} \mathrm{O} /(1-0.07 x), \\
& \left.r \mathrm{CO}_{2}=\left[\left(r^{\prime} \mathrm{H}_{2} \mathrm{O}+r^{\prime} \mathrm{CO}_{2}\right)-r^{\prime} \mathrm{H}_{2} \mathrm{O}(1-0.01 x) / 1-0.07 x\right)\right] \times 0.962
\end{aligned}
$$


Table 1. Some demographic characteristics of the infants recruited into the study

\begin{tabular}{lc}
\hline Gestational age (weeks) & $\begin{array}{c}\text { Mean 39.9, } \\
\text { SD 1.34 } \\
\text { Mean 3513, } \\
\text { Birth wt (g) }\end{array}$ \\
SD 419 \\
Percentage of infants & \\
Standard vaginal delivery & 68 \\
Caesarian section & 17 \\
Male & 39 \\
Breast-fed & 51 \\
Social classes 1 and 2 & 63 \\
Social classes 3 and 4 & 27 \\
\hline
\end{tabular}

Table 2. Age, height, weight and energy expenditure of the cohort of full-term infants studied

(Mean values and standard deviations)

\begin{tabular}{|c|c|c|c|c|c|c|c|c|c|c|}
\hline \multirow[b]{3}{*}{ Period } & \multirow[b]{3}{*}{$n$} & \multirow{3}{*}{$\begin{array}{c}\begin{array}{c}\text { Age } \\
(\mathrm{d})\end{array} \\
\text { Mean SD }\end{array}$} & \multirow{2}{*}{\multicolumn{2}{|c|}{$\begin{array}{l}W \mathfrak{t} \\
(\mathrm{g})\end{array}$}} & \multirow{3}{*}{$\begin{array}{c}\begin{array}{c}\text { Length } \\
(\mathrm{mm})\end{array} \\
\text { Mean SD }\end{array}$} & \multicolumn{5}{|c|}{ Energy expenditure } \\
\hline & & & & & & \multicolumn{3}{|c|}{$\mathrm{kJ} / \mathrm{d}$} & \multicolumn{2}{|c|}{$\mathrm{kJ} / \mathrm{kg}$ per d } \\
\hline & & & Mean & $\mathrm{SD}$ & & Mean & SD & Range & Mean SD & Range \\
\hline A & 39 & $363 \cdot 2$ & 4653 & 397 & $551 \quad 16$ & 1280 & 390 & $690 \cdot 2340$ & $270 \quad 70$ & $130-430$ \\
\hline B & 40 & $774 \cdot 0$ & 5792 & 468 & $592 \quad 17$ & 1640 & 400 & $830-2720$ & $280 \quad 60$ & $130-480$ \\
\hline $\mathrm{C}$ & 37 & $1815 \cdot 1$ & 7704 & 773 & $667 \quad 21$ & 2530 & 420 & $1660-3580$ & $330 \quad 50$ & $190-460$ \\
\hline
\end{tabular}

A, 6 weeks; B, 3 months; C, 6 months.

Assuming a respiratory quotient (RQ) of 0.870 at periods $\mathrm{A}$ and $\mathrm{B}$ and 0.855 at period C (Black et al. 1986), total energy expenditure can be calculated using Weir's (1949) formula. Classical anthropometry, including measurements of supine length, was undertaken. Body-weight was measured to the nearest $g$ at the beginning and end of the study period.

\section{RESULTS}

Table 1 shows a number of the demographic characteristics of the infants recruited for the present study. The means and standard deviations of age, length and weight and the means and standard deviations and range for total energy expenditure are shown in Table 2. Dose loss, caused by posseting or vomiting during or immediately following the administration of the dose, resulted in a loss of two, one and four data points at periods $\mathrm{A}, \mathrm{B}$ and $\mathrm{C}$ respectively. The means and standard deviations of the isotopic enrichments in the predose urine samples, the disappearance rate constants $k_{0}$ and $k_{\mathrm{d}}$ and the intercepts of the regression lines of log enrichment $v$. time are shown in Table 3.

Energy expenditure is often expressed per $\mathrm{kg}$ body-weight, so that the measurement is independent of body-weight. Recent statistical work (Davies et al. 1989) has shown that in early infancy the expression of energy expenditure is minimally correlated with bodyweight when the square root of body-weight is used as the denominator. Basal energy expenditure is often expressed per $\mathrm{kg}$ lean body mass, as this probably reflects the metabolically active portion of the body. Basal and total energy expenditure are closer in early infancy than in later childhood and adulthood. Thus, lean body mass may also be an appropriate denominator for the expression of total energy expenditure in young infants. 
Table 3. Pre-dose isotope enrichments, rate constants $\left(k_{d}, k_{o}\right)$ and intercepts of the regression lines for the cohort of full-term infants studied*

\begin{tabular}{|c|c|c|c|c|c|c|}
\hline \multirow[t]{2}{*}{ Period... } & \multicolumn{2}{|c|}{ A } & \multicolumn{2}{|c|}{ B } & \multicolumn{2}{|c|}{$\mathrm{C}$} \\
\hline & Mean & SD & Mean & SD & Mean & SD \\
\hline $\begin{array}{l}{ }^{2} \mathrm{H} \text { enrichment in } \\
\text { predose urine }(\%)\end{array}$ & $21 \cdot 5$ & $7 \cdot 2$ & $21 \cdot 1$ & $7 \cdot 8$ & $21 \cdot 9$ & $7 \cdot 0$ \\
\hline $\begin{array}{l}{ }^{18} \mathrm{O} \text { enrichment in } \\
\text { predose urine }(\%)\end{array}$ & $3 \cdot 4$ & $1 \cdot 5$ & $3 \cdot 6$ & $1 \cdot 7$ & $3 \cdot 7$ & $1 \cdot 3$ \\
\hline$k_{\mathrm{r}}$ & $0 \cdot 251$ & 0.032 & $0 \cdot 239$ & 0.030 & $0 \cdot 221$ & 0.034 \\
\hline$k_{\mathrm{o}}$ & $0 \cdot 292$ & 0.035 & $0 \cdot 282$ & 0.032 & $0 \cdot 268$ & 0.037 \\
\hline${ }^{2}{ }_{\mathrm{H}}^{\mathrm{H}}$ intercept & $1065 \cdot 2$ & $170 \cdot 9$ & $1090 \cdot 2$ & $160 \cdot 4$ & $1461 \cdot 8$ & $169 \cdot 0$ \\
\hline${ }^{18} \mathrm{O}$ intercept & $215 \cdot 0$ & $34 \cdot 8$ & $223 \cdot 7$ & $28 \cdot 5$ & $230 \cdot 6$ & $27 \cdot 5$ \\
\hline
\end{tabular}

* For details of calculations, see p. 622.

Table 4. Energy expenditure expressed as the geometric mean and coefficient of variation (log $S D ; C V)$ for the cohort of full-term infants studied. The data were used to calculate the centile charts shown in Figs 1-3

\begin{tabular}{|c|c|c|c|c|c|c|c|}
\hline \multirow[b]{2}{*}{ Period } & \multirow[b]{2}{*}{$n$} & \multicolumn{2}{|c|}{$\begin{array}{l}\text { Energy expenditure } \\
(\mathrm{kJ} / \mathrm{d})\end{array}$} & \multicolumn{2}{|c|}{$\begin{array}{l}\text { Energy expenditure } \\
(\mathrm{kJ} / \sqrt{\mathrm{kg}} \text { per } \mathrm{d})\end{array}$} & \multicolumn{2}{|c|}{$\begin{array}{c}\text { Energy expenditure } \\
(\mathrm{kJ} / \mathrm{kg} \text { fat-free mass per } \mathrm{d})\end{array}$} \\
\hline & & $\begin{array}{c}\text { Geometric } \\
\text { mean }\end{array}$ & $\mathrm{CV}$ & $\begin{array}{l}\text { Geometric } \\
\text { mean }\end{array}$ & $\mathrm{CV}$ & $\begin{array}{l}\text { Geometric } \\
\text { mean }\end{array}$ & $\mathrm{CV}$ \\
\hline A & 39 & 1224 & 0.300 & 568 & 0.289 & 331 & 0.278 \\
\hline B & 40 & 1588 & 0.247 & 661 & 0.244 & 362 & 0.230 \\
\hline $\mathrm{C}$ & 37 & 2493 & 0.167 & 901 & 0.157 & 449 & 0.140 \\
\hline
\end{tabular}

Any centile $(C)$ can be calculated from $C_{\mathrm{Z}}=M \times \exp (S Z)$ where $Z$ is the normal equivalent deviate of the centile required, $S$ is the $\log \mathrm{SD}$ or $\mathrm{CV}$, and $M$ is the geometric mean.

Lean body mass was calculated from the measurement of total body water inherent in the doubly-labelled-water technique. The values of Fomon et al. (1982) for the proportion of water in lean tissue were used to derive lean body mass from total body water. However, when expressed in all these ways the values were positively skewed. A logarithmic transformation removed this skewness. Centile charts for total energy expenditure and energy expended per square root body-weight are shown in Figs. 1 and 2 respectively. Centiles for total energy expenditure per kg lean body mass are shown in Fig. 3. In all cases the centiles are derived from the means and standard deviations of the log transformed values. The geometric means and coefficient of variation (log standard deviation) for energy expenditure used to calculate the centiles are shown in Table 4. The centiles were not smoothed; straight lines were used to join the data points at each period.

\section{DISCUSSION}

We have used the newly validated doubly-labelled-water technique to measure noninvasively total energy expenditure over a period of $7 \mathrm{~d}$ to provide the first centiles for total energy expenditure for infants up to 6 months of age. There are two basic methods by which the centiles we have presented could have been calculated. First, the values at each age could have been ranked and the centiles estimated directly by counting up from the bottom. 


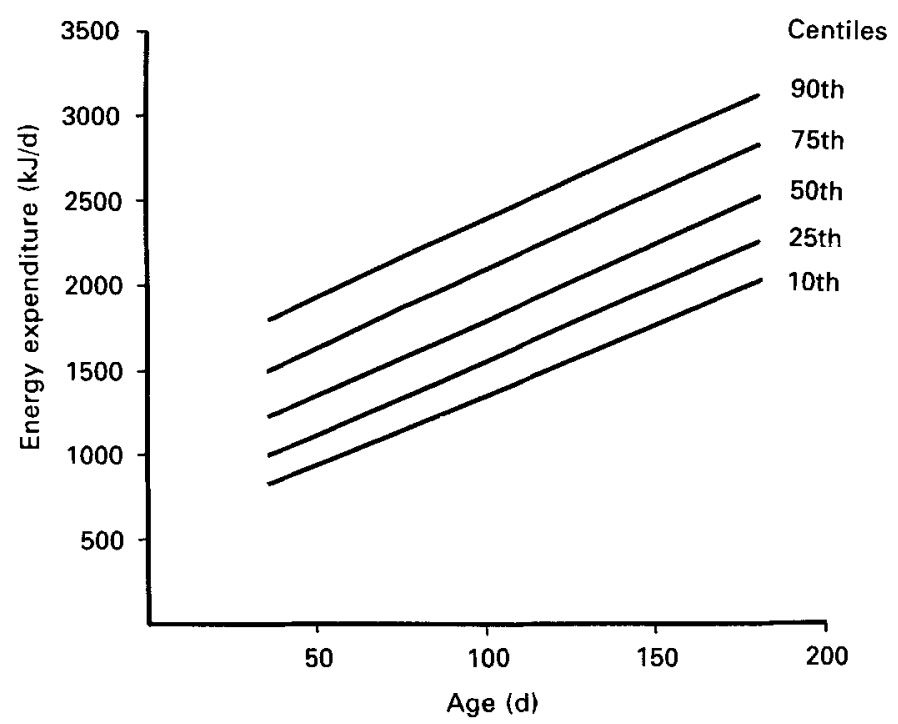

Fig. 1. Centiles for total energy expenditure $v$. age derived from mean and standard deviations of the log transformed raw values for a cohort of full-term infants (for details, see Table 1).

Second, centiles could have been calculated from the means and standard deviations of the values, assuming normality. We adopted the latter technique.

The efficiency of the non-parametric technique is substantially less than the use of means and standard deviations. Healy (1974) calculated that at the more extreme centiles, such as the $3 \mathrm{rd}$ centile, approximately four times as many subjects are required to obtain the same precision when using a non-parametric method as when using a parametric method.

There are a number of potential sources of error in the doubly-labelled-water technique that need careful consideration. These include the choice of $R Q$, the proportion of water output fractionated, the possible sequestration of isotope into body tissue, and the effect of weaning or major changes in diet during an isotope study period.

In adult studies using the doubly-labelled-water technique an RQ of 0.85 is usually used. Although RQ may vary throughout a study, over a period of 10-14 d, the length of most adult studies, RQ will tend towards 0.85 and the use of this value will not introduce a large error. However, an RQ value used in infants must take into account growth. Black et al. (1986) list unadjusted and adjusted food quotients (FQ) for infants, and conclude that FQ and $R Q$ can be used interchangeably in the doubly-labelled-water technique, due to the length of study period ( $7 \mathrm{~d}$ in our study). The value for RQ we have used at periods $\mathrm{A}$ and B (i.e. 0.87) is the mean of some 143 individual calculations of FQ, adjusted to allow for growth using the body composition values of Fomon (1974). At period C an adjusted FQ of 0.855 is used; this is based on 253 individual measurements of FQ between the ages of 4 and 12 months. Consequently we feel that our choice of $R Q$ is appropriate and justified.

Another source of potential error in the doubly-labelled-water technique is the use of an inappropriate value for the proportion of total water output that is subject to isotopic fractionation (fractionation factor). The magnitude of error produced in the final estimation of total energy expenditure due to an inappropriate choice of fractionation factor depends strongly on the $k_{\mathrm{d}}: k_{\mathrm{o}}$ value. The closer this ratio is to 1 the greater the final error. In adults the $k_{\mathrm{d}}: k_{\mathrm{o}}$ value is usually about 0.75 . In young infants, as water turnover is high in relation to $\mathrm{CO}_{2}$ production rate, the ratio is higher $(0 \cdot 86,0 \cdot 85$ and 0.82 at periods 


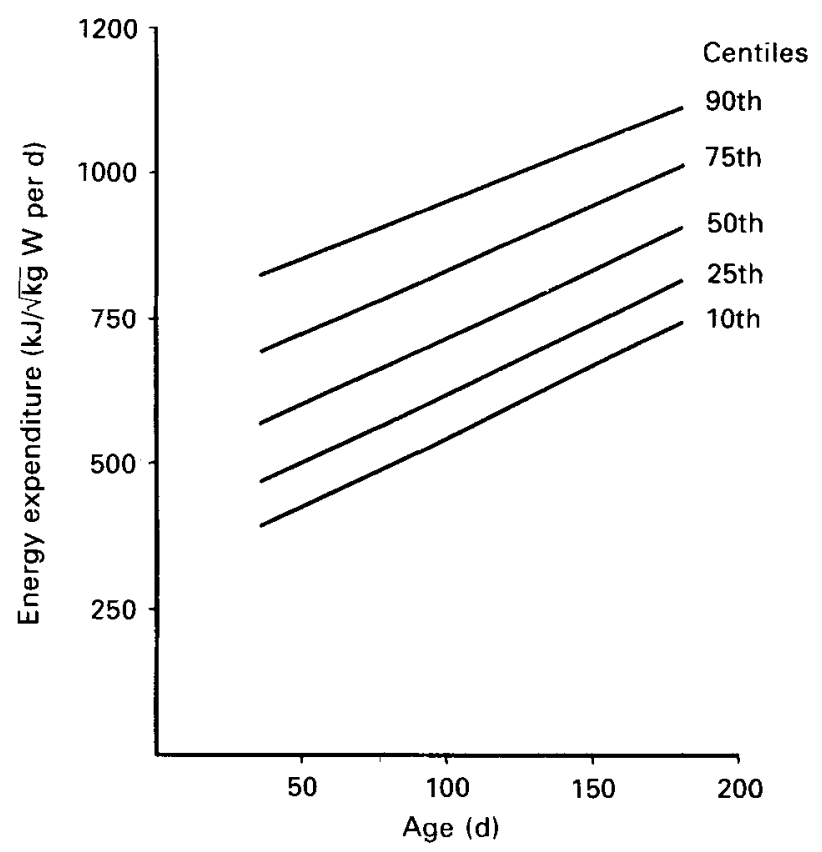

Fig. 2. Centiles for total energy expenditure expressed on a body-weight (W) basis $v$. age for a cohort of full-term infants (for details, see Table 1).

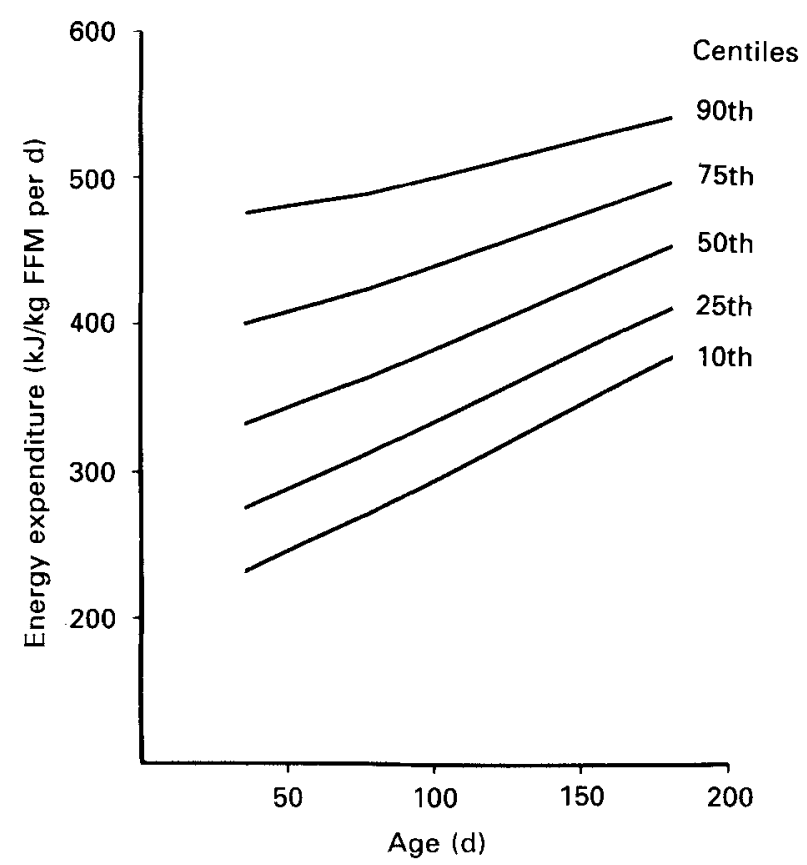

Fig. 3. Centiles for total energy expenditure expressed on a $\mathrm{kg}$ fat-free mass (FFM) basis $v$. age for a cohort of full-term infants (for details, see Table 1). 
A, B and C respectively in the present study). Coward (1988) recently showed that with a $k_{\mathrm{d}}: k_{\mathrm{o}}$ value of 0.90 as much as an $8 \%$ error in $\mathrm{CO}_{2}$ production rate will be induced by an error of 0.1 in the value of fractionation factor used. The factor assumed in the present study $(0.13)$ is based on an unpublished water balance study (A. Lucas, unpublished results), in a subset of infants in the present cohort.

In the validation study of Jones et al. (1987) a higher value (0.18) was used. This value was based on the assumptions that breath is saturated with water and contains $3.5 \% \mathrm{CO}_{2}$. Thus breath water losses can be related to $\mathrm{CO}_{2}$ production rate. Skin losses (non-sweat) were estimated using a value of $0.18 \mathrm{~g} / \mathrm{min}$ per $\mathrm{m}^{2}$ insensible skin water loss, and assuming that $75 \%$ of the infant's skin was exposed to the air. While appropriate for the infants studied by Jones et al. (1987), their assumed value for the proportion of exposed skin was undoubtedly too high for the infants in our study. We estimate a value of about $30 \%$ would be more appropriate. Using this, and the approach of Jones et al. (1987), the mean proportion of water output fractionated in our study would have been $0 \cdot 15$, close to our value of $0 \cdot 13$.

The sequestration of isotope into tissues during the rapid growth experienced during early infancy could lead to error in the calculation of total energy expenditure. Labelled $\mathrm{H}$ exchanges with non-aqueous $\mathrm{H}$ in proteins and other tissues. In contrast, there is little nonaqueous $\mathrm{O}_{2}$ in the body with which ${ }^{18} \mathrm{O}$ could exchange, and in any case such an exchange does not occur readily at physiological temperature and $\mathrm{pH}$. Jones et al. (1987) addressed the potential problem of label sequestration in rapidly growing infants. They hypothesized that if there was significant isotope sequestration, notably of labelled $H$, the difference in energy expenditure (calculated by doubly-labelled water) and respiratory gas exchange would be correlated with the change in body-weight during the study period. No such relationship was found and these workers concluded that sequestration rates were insignificant.

Finally, changes in the enrichment of ${ }^{2} \mathrm{H}$ and ${ }^{18} \mathrm{O}$ in dietary water during a study period can produce major errors in the calculation of energy expenditure with doubly-labelled water (Jones et al. 1988; Roberts et al. 1988a). During infancy the principal factor in the change in dietary water ${ }^{2} \mathrm{H}$ and ${ }^{18} \mathrm{O}$ content is weaning. At periods $\mathrm{A}$ and $\mathrm{B}$ the infants studied here were being breast-fed or formula-fed exclusively, while at period C, care was taken that no major changes in diet occurred during the study period.

During the first 6 months of life total energy expenditure per day increased by almost $100 \%$. When the same values were expressed per $\mathrm{kg}$ body-weight the increase was less dramatic, showing a $20 \%$ rise. When adjusting energy expenditure for body-weight it is important that these two variables are uncorrelated. In a detailed statistical analysis (Davies et al. 1989) the inter-relationship between energy expenditure and body-weight was minimized when the square root of body-weight was used as the denominator. Therefore, this method of expressing the values was used to construct centile lines. The centiles showed a slight convergence at 6 months of age. The range between the 10th and 90th centiles was $430 \mathrm{~kJ} / \sqrt{ } \mathrm{kg}$ at 5 weeks of age which diminished to $320 \mathrm{~kJ} / \sqrt{\mathrm{kg}}$ at 6 months of age. This convergence of the centile lines is contrary to expectation. It would be reasonable to assume that infants vary more in their levels of physical activity at 6 months of age than at 6 weeks, and that this would be reflected in a wider range of total energy expenditure. This observation may have a methodological basis. The doubly-labelled-water method is used to detect the difference between the disappearance rates from body fluids of ${ }^{18} \mathrm{O}$ and ${ }^{2} \mathrm{H}$, this difference reflecting $\mathrm{CO}_{2}$ production rate and hence energy expenditure. However, in infancy water turnover is high and the disappearance rates of ${ }^{18} \mathrm{O}$ and ${ }^{2} \mathrm{H}$ are very close. The closeness of the two disappearance rates influences the precision with which $\mathrm{CO}_{2}$ production rates can be estimated. Thus, a greater error in the estimation of energy 
expenditure may have occurred in the earlier age-group when water turnover was highest. Nevertheless the possibility that the convergence in energy expenditure centiles had, at least in part, a biological explanation cannot be discounted; and further work is required to explore whether there is a tighter physiological control of total energy expenditure at 6 months than at 6 weeks.

The range of energy expenditure values shown in Fig. 2 is large, notably at periods $A$ and B. It might be suggested that the more extreme values are due to methodological error. However, it is noteworthy that the lowest values for total energy expenditure at periods $\mathrm{A}$ and $B$ were obtained from the same child. This child also had one of the lowest values of total energy expenditure found at period C. Thus, the low energy expenditures found in some individuals may be biological rather than due, principally, to methodological error.

The subjects recruited for the present study were normal, full-term babies including those who were breast- and bottle-fed. It is likely they were representative of British infants. Mean birth weight (sexes combined) was only 0.13 standard deviation scores above the mean in comparison with reference values (Tanner, 1973), and a similar trivial difference was found at 6 months. Mean supine length at 6 months differed from reference values by only 0.06 standard deviation scores. These findings provide further supportive evidence that the recruited subjects were not atypical.

When energy stored in new tissue (Fomon et al. 1982; Lucas et al. 1987) is combined with values for energy expenditure, energy intake can be derived. Such intake values have been used as a basis for estimating energy requirements. The information on energy expenditure presented here together with our previous observations (Lucas et al. 1987; Prentice et al. 1988) add increasing weight to the view that energy requirements of healthy infants may have been substantially overestimated using previously available techniques.

The doubly-labelled-water technique allows the detailed study of energy metabolism in health and disease; it has major benefits over other methods for studies on infants because of the safe, non-invasive and simple nature of the procedures. The findings here will be of value as reference values for estimating the energy needs of healthy infants and for use in studies designed to examine energy metabolism in disease states.

The authors acknowledge financial support from Farley Health Products Ltd and Ross Laboratories.

\section{REFERENCES}

Black, A. E., Prentice, A. M. \& Coward, W. A. (1986). Use of food quotients to predict respiratory quotients for the doubly-labelled water method of measuring energy expenditure. Human Nutrition: Clinical Nutrition 40C, 381-391.

Coward, W. A. (1988). The doubly-labelled water $\left({ }^{2} \mathrm{H}_{2}{ }^{18} \mathrm{O}\right)$ method: principles and practice. Proceedings of the Nutrition Society 47, 209-218.

Davies, P. S. W., Cole, T. J. \& Lucas, A. (1989). Adjusting energy expenditure for body weight in early infancy. European Journal of Clinical Nutrition (In the press).

Department of Health and Social Security (1979). Recommended daily amounts of food energy and nutrients for groups of people in the United Kingdom. Report on Health and Social Subjects no. 15. London: H.M. Stationery Office.

Fomon, S. J. (1974). Infant Nutrition, 2nd ed. Philadelphia: W. B. Saunders

Fomon, S. J., Haschke, F., Ziegler, E. E. \& Nelson, S. E. (1982). Body composition of reference children from birth to age 10 years. American Journal of Clinical Nutrition 35, 1169-1175.

Healy, M. J. R. (1974). Notes on the statistics of growth standards. Annals of Human Biology 1, 41-46.

Jones, P. J. H., Winthrop, A. L., Schoeller, D. A., Filler, R. M., Swyer, P. R., Smith, J. \& Heim, T. (1988). Evaluation of doubly labelled water for measuring energy expenditure during changing nutrition. American Journal of Clinical Nutrition 47, 799-804.

Jones, P. J. H., Winthrop, A. L., Schoeller, D. A., Swyer, P. R., Smith, J., Filler, R. M. \& Heim, T. (1987). Validation of doubly labelled water for assessing energy expenditure in infants. Pediatric Research 21, 242-246. 
Lucas, A., Ewing, G., Roberts, S. B. \& Coward, W. A. (1987). How much energy does the breast-fed infant consume and expend? British Medical Journal 295, 75-77.

Prentice, A. M., Lucas, A., Vasquez-Velasquez, L., Davies, P. S. W. \& Whitehead, R. G. (1988). Are current dietary guidelines for young children a prescription for overfeeding? Lancet ii, 1066-1069.

Roberts, S. B., Coward, W. A., Ewing, G., Savage, J., Cole, T. J. \& Lucas, A. (1988a). Effect of weaning or accuracy of doubly labelled water method in infants. American Journal of Physiology 254, R622-R627.

Roberts, S. B., Coward, W. A., Schlingenseipen, K. H., Nohna, V. \& Lucas, A. (1986). Comparison of the doubly labelled water $\left({ }^{2} \mathrm{H}_{2}{ }^{18} \mathrm{O}\right)$ method with indirect calorimetry and a nutrient balance study for simultaneous determination of energy expenditure, water intake and metabolizable energy intake in preterm infants. American Journal of Clinical Nutrition 44, 315-322.

Roberts, S. B., Savage, J., Coward, W. A., Chew, B. \& Lucas, A. (1988b). Energy expenditure and intake in infants born to lean and overweight mothers. New England Journal of Medicine 318, 461-466.

Shepherd, R. W., Holt, T. L., Vasquez-Velasquez, L., Coward, W. A., Prentice, A. \& Lucas, A. (1988). Increased energy expenditure in young children with cystic fibrosis. Lancet $\mathbf{i}, 1300-1303$.

Tanner, J. M. (1973). Physical growth and development. In Textbook of Paediatrics, pp. 224-292. [J. O. Forfar and G. C. Arneil, editors]. Edinburgh: Churchill Livingstone.

Weir, J. B. de V. (1949). New method for calculating metabolic rate with special reference to protein metabolism. Journal of Physiology 109, 1-9. 